Discussion Paper No. 08-098

Do Shorter Product Cycles Induce Patent Thickets?

Patrick Beschorner

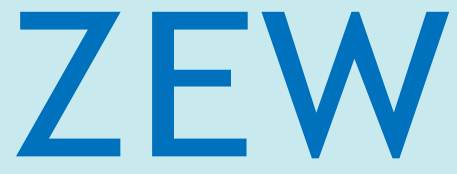

Zentrum für Europäische Wirtschaftsforschung $\mathrm{GmbH}$

Centre for European

Economic Research 
Discussion Paper No. 08-098

\title{
Do Shorter Product Cycles Induce Patent Thickets?
}

\author{
Patrick Beschorner
}

Download this ZEW Discussion Paper from our ftp server:

ftp://ftp.zew.de/pub/zew-docs/dp/dp08098.pdf

Die Discussion Papers dienen einer möglichst schnellen Verbreitung von neueren Forschungsarbeiten des ZEW. Die Beiträge liegen in alleiniger Verantwortung der Autoren und stellen nicht notwendigerweise die Meinung des ZEW dar.

Discussion Papers are intended to make results of ZEW research promptly available to other economists in order to encourage discussion and suggestions for revisions. The authors are solely responsible for the contents which do not necessarily represent the opinion of the ZEW. 


\section{Executive Summary}

The traditional argument that shorter product cycles favor trade secrets over patenting is based on the presumption that copying becomes less profitable and trade secrets less likely to be discovered when a technology can be used for a shortened time period only. I review this argument. Under certain circumstances shorter product cycles can generate incentives to apply for more patents and the consequence may be the emergence of a patent thicket.

In the model the underlying mechanism for the more intensive patenting activity is that one firm may start to raise its number of patent applications for exogenous reasons and the optimal reaction of other firms is then to match this behavior. Otherwise, the extensive patenting of one firm would drive the other firms out of the market or cut their profits significantly. In order to prevent this, the other firms start filing patent applications on many ideas, which are not mature yet but may turn out successful eventually, instead of few fully developed technologies. If this situation occurs the firms may end up in a prisoners' dilemma where they would jointly prefer the situation where all firms innovate at moderate pace but each individual firm has an incentive to deviate to a short cycle with intensive patenting.

Further, network effects may reinforce a firm's incentive to accelerate her R\&D process and to induce other firms to adopt this strategy. Network effects make it more attractive to gain market shares at an early stage because an advance compared to the competitors will be persistent. Therefore, the model predicts an intensive race by means of patent applications followed by a period of attenuated innovative activities. Similarly, blocking patents provide an advantage over competitors by limiting their access to technologies. But, in contrast to network effects, this is socially harmful because some R\&D effort is wasted. Therefore, firms will patent less because their R\&D tends to be less efficient.

Licensing is an appropriate remedy to blocking patents and patent thickets and policy should facilitate licensing agreements in order to benefit from technologies that would otherwise lie idle. 


\section{Zusammenfassung}

Das Argument, kürzere Produktlebenszyklen würden zu einem verstärkten Einsatz von Geheimhaltung statt Patentierens führen, basiert auf dem Effekt, dass Nachahmen weniger lohnend und Geheimhaltung effektiver werden. Die Überprüfung dieses Arguments zeigt, dass unter bestimmten Bedingungen der gegenteilige Effekt eintreten kann. Verkürzte Produktlebenszyklen können dazu führen, dass vermehrt Patentanmeldungen eingereicht werden. In der Folge ist es wahrscheinlicher, dass Patentdickichte entstehen.

Im Modell bewirkt das verstärkte Patentieren durch ein Unternehmen, dass andere Unternehmen gezwungen werden, dieses Verhalten nachzuahmen. Andernfalls würden sie den Zugriff auf neue Technologien verlieren oder zumindest starke Gewinneinbußen erleiden. Um dies zu verhindern, beginnen auch die anderen Unternehmen zahlreiche, noch nicht ausgereifte Ideen, die sich erst später als erfolgreich herausstellen können, zum Patent anzumelden, statt nur wenige, ausgereifte Technologien anzumelden. Wenn diese Situation eintritt, befinden sich die Unternehmen in einem Gefangenendilemma: Jedes von ihnen bevorzugt die Situation, in der alle moderat patentieren. Wenn alle Unternehmen diese Strategie verfolgen hat jedes Unternehmen einen individuellen Anreiz doch wieder verstärkt zu patentieren.

Das Vorliegen von Netzwerkeffekten verstärkt den Anreiz für jedes Unternehmen seine F\&E-Intensität zu erhöhen. Dieser Effekt bewirkt, dass es für Unternehmen besonders profitabel ist, frühzeitig Marktanteile zu erlangen, weil sein größerer Marktanteil ein Unternehmen besonders attraktiv für neue Kunden macht. Deshalb sagt das Modell für solche Industrien einen anfangs verstärkten, später nachlassenden Technologiewettbewerb voraus. In gleicher Weise bewirken blockierende Patente, dass ihre Inhaber einen Vorteil gegenüber Wettbewerbern erlangen. Dies sind Patente, die für eine bestimmte Technologie essenziell sind. Im Gegensatz zu Netzwerkeffekten beruht die Wirkung von blockierenden Patenten darauf, dass F\&E Aufwendungen obsolet werden. Daher reduziert sich der Anreiz von Unternehmen zu patentieren, weil F\&E-Investitionen weniger produktiv werden.

Lizenzen sind ein wirksames Instrument, um Patentdickichte und die blockierende Wirkung von Patenten aufzulösen. Solche Vereinbarungen zwischen Unternehmen sollten vereinfacht werden, damit Technologien, die nur aufgrund von Patentdickichten brach liegen, eingesetzt werden können. 


\title{
Do shorter product cycles induce patent thickets?
}

\author{
Patrick F.E. Beschorner* \\ first draft: September 2008 \\ this version: December 4, 2008
}

\begin{abstract}
The traditional argument that shorter product cycles favor trade secret over patenting is reviewed. A game theoretic model provides an argument that shorter product cycles can induce firms to file more patent applications. The firms may be trapped in a prisoners' dilemma where all firms would jointly prefer to patent less and to not have a patent thicket. If firms start applying for patents on technologies which are not yet mature in order to cover ideas that may eventually turn successful, this may create a patent thicket. The transition into a situation where firms start patenting many ideas instead of single mature technologies is initiated and accelerated when network effects are present or patents exhibit a blocking property.
\end{abstract}

Keywords: patent thicket, product cycles, licensing, network effects JEL: L1, L2, O31, K2

*ZEW Centre for European Economic Research, Mannheim, P.O.Box 103443 , 68034 Mannheim, Germany, tel. +49-(0)621-1235-175, fax. +49-(0)621-1235-170, beschorner@zew.de. This paper was written while I was a visiting researcher at U.C. Berkeley. I thank the Department of Economics and Prof. Bronwyn Hall for their hospitality. Financial Support from the Deutsche Forschungsgemeinschaft through SFB/TR15 and from RNIC Research Network on Innovation and Competition Policy is gratefully acknowledged. 


\section{Introduction}

Where does the patent thicket come from? Some industries tend to produce patent applications which result in overlapping property rights, for example the ICT sector, biotechnologies or the software industry. ${ }^{1}$ Using one's own patents may inevitably infringe upon other parties' patents. Thus, patents can be used in order to block others from exploiting their patents or hinder them to develop competing products based on their own patents. ${ }^{2}$ In less severe cases the fragmentation of intellectual property rights leads to a cost rise for developing marketable products. Overall, this may result in an disincentive for innovation. ${ }^{3}$

There are several explanations for the emergence of patent thickets ${ }^{4}$ and the so-called patent surge or patent explosion ${ }^{5}$. The present paper conjectures that a shorter product cycle can induce a higher propensity to patent. This contrasts with the intuition that a shorter time for recouping the investment for a technology renders secrecy more attractive than patenting, thus the shortening of product cycles is contented to reduce the propensity to patent.

Sabety (2004) provides an exemplary comparison of the information technology industry, where software was originally considered not patetentable subject mater, whereas in nanotechnology patentability has never been questioned. In both industries patent thickets are emerging and this hampers or delays further innovation, but nanotechnology is a comparatively juvenile industry. In order to allow this industry to live a long period of jaunty development as did the software industry before, he recommends to adopt a similar IP schedule where the strength of IP protection should raise with

\footnotetext{
${ }^{1}$ See Shapiro (2001), Sabety (2004).

${ }^{2}$ See Heller and Eisenberg (1998).

${ }^{3}$ See Merges and Nelson (1990).

${ }^{4}$ A detailed discussion is provided for example by Shapiro (2001).

${ }^{5}$ See Kortum and Lerner (1998) or Sanyal and Jaffee (2007).
} 
maturity of the industry in order to avoid blocking situations in the early stage.

The remainder of the paper is structured as follows. The next subsections will provide reference to related work and present the intuition for the model setting. Section 2 sets up the model, which is discussed in section 3. Section 4 provides extensions on network effects, blocking patents, and licensing. Section 5 concludes.

\subsection{Related Work}

There is a strand of literature on sequential improvements of products. A detailed discussion of IP policy in the context of quality ladders is provided by Scotchmer (2004). The firm strategies on sequential innovations and the afflicting factors on the decision to introduce incremental innovations or frontier innovations are analyzed by Gjerde et al. (2002).

Another strand of literature on product cycles and international trade is based on heterogeneous firms. Models with a high ability to innovate in the North region face imitators or a less productive South region. Based on this idea by Vernon (1966) several refinements of this model confirm the robustness of his result that the firm (country) endowed with a technological advance keeps this advantage. Segerstrom et al. (1990) find that trade tariffs that protect from the imitating country's lower labor cost reduce overall the innovative activity in an economy. Similarly, extending the present model by blocking patents results in the effect that $R \& D$ activities become less productive and, thus, less attractive to firms. Grossman and Helpman (1991) analyze heterogenous countries in a general equilibrium model. The countries differ in their ability to innovate and they can imitate or innovate and this determines endogenously the product cycle. They study how the 
sizes of the two regions and the levels of support or subsidies for R\&D affect the long-run rates of innovation and imitation and, finally, how this afflicts the length of the average product cycle. I will adopt from their setting that the innovator earns the monopoly payoff and that the $R \& D$ decision is to be taken repeatedly. However, in contrast to their model with asymmetric countries, I focus on symmetric firms because this paper aims at analyzing the patenting strategies of firms on a level playing field. This is a presumption in part of the literature on endogenous growth, e.g. Aghion and Howitt (1992), where the research question aims at an optimal policy for aggregate production or knowledge growth. However, I consider the interaction among R\&D conducting firms whereas that strand of literature stylizes this interaction as spillovers.

The timing of introducing new products with consideration of the tradeoff between time to market, resources spent, and the degree of novelty has been inter alia analyzed by Reinganum (1989), Fudenberg and Tirole (1984), Tirole (1990) and Hendricks (1992). Similarly, concentrating on the adoption of single innovations, the present model builds on these insights and focuses on the use of patent applications as an instrument to pursue these strategies. A model allowing for incremental innovations as well as frontier innovations is provided by Gjerde et al. (2002).

\section{$1.2 \quad$ The Story}

I analyze the firms' incentive to patent as a reaction to their competitors' patenting strategies. Thereby, patenting is an instrument to support an accelerated $R \& D$ process and to induce a shortening of product life cycles.

Products are regularly modified and updated to meet the current consumers' expectations, regulatory norms, or state of the art. In the automobil 
industry model years show up minor modifications up to a change in the model cycle where a new body or a new series of engines is built in. Similarly, computers, i.e. the CPU, have shown a typical evolvement in performance and the generations of CPU have been named i86 and Pentium, Pentium2, Pentium3, ... ${ }^{6}$ Further, we observe that product life cycles tend to become shorter. ${ }^{7}$ One reason in the automotive sector is that the design is done with more advanced software and many time-consuming processes were replaced or accelerated by use of computers. Other reasons are that both the production and development processes have been reorganized, such that the role of IP became more important. 8 Whimsical observers of the market proclaim that the test phase for new vehicles has been shifted to the early buyers, leading to a surge in lemon cars.

In the present analysis, I focus on products where patent protection is immanent. This means that any innovation is patented because it may be too easy to copy, e.g. by reverse engineering. Thus, I do not focus on the trade-off between secrecy and protection. This would attack on a distinct branch of literature which has been analyzed to a broad extent (See Cohen, Nelson, and Walsh (2000), Gallini (2002)).

As in Ofek and Savary (2004), I model a very stylized demand behavior of the consumers who strictly prefer a new generation product as soon as this becomes available. A firm that offers a predecessor model will make no sales. This extreme demand structure is primarily helpful for the handling of the model structure. In fact, there exists evidence that firms have to offer extensive discounts to sell new products stemming from an outdated product life cycle. In the automotive industry passed year models are sold with high

\footnotetext{
${ }^{6}$ See Ofek and Sarvary (2003).

${ }^{7}$ See Agarwal and Gort (2001).

${ }^{8}$ See Teece et al. (1997), Pisano and Teece (2007).
} 
rebates as soon as the next model year becomes available. ${ }^{9}$ This stylized distribution of demand can be derived from individual utility maximizing behavior, e.g. in Shaked and Sutton (1982) or Mussa and Rosen (1978) where ex ante symmetric firms offer vertically differentiated products. Each firm prefers to offer the higher quality product and these two models do not explain which firms takes which role.

For the R\&D process I assume that firms have a number of ideas on how to develop a technology and that finding the appropriate technology is a time-consuming process. At the patenting stage, a firm may not yet know which of its ideas will turn out to be valuable and will lead to a marketable product. Thus, finally one out of many ideas turns out to be the basis of a new technology and will be developed, which then will be patented. Realizing these steps one by one will take time that delays the marketing of the new product. However, each of these steps is essential and cannot be circumvented. But the process can be accelerated if a firm is applying for patents on many promising technologies before she finds out which actually is the successful technology. Thus, more than the successful idea is patented. This strategy allows to protect potentially tractable technologies before the final decision is taken on which one is to be carried out up to the final product. Advocates of patent continuations contend that defining an invention is a complex process and it may become necessary to amend the scope of protection that is claimed in the original application. This practice is common at the USPTO but continuing patent applications are not admissible the EPO. Still, firms can file many applications. ${ }^{10}$

I will distinguish a long and a short $\mathrm{R} \& \mathrm{D}$ schedule $L$ and $S$, respectively. In the long schedule the firms first develop an idea into a technology, which is patented subsequently. In contrast in the short schedule several ideas are

\footnotetext{
${ }^{9}$ See Langer and Miller (2008).

${ }^{10}$ See Katznelson (2007).
} 
patented before the successful idea has been identified. Thus, the final technology is based on a patented idea and the protection of other ideas becomes obsolete even though these ideas eventually are granted patent protection. These patents together with countless pending patent applications may over time create a patent thicket with overlapping intellectual property rights and create uncertainty. ${ }^{11}$ Sometimes continuations with amended sham claims are filed in order to cover a competitor's product. ${ }^{12}$ This procedure is not covered by the Patent Examining Procudure, although it can occur. ${ }^{13}$

In our model each of the two schedules will have pros and cons. Basically, the short cycle offers the chance to market a new product cycle earlier than under the long cycle. However, there is a higher cost because more patent applications are filed. Also R\&D may be conducted more intensively or the search of prior art must be conducted more accurately because this information must be available earlier than the accomplishment of the patent search report. In contrast, the long cycle has fewer costs and upon completion the $\mathrm{R} \& \mathrm{D}$ process provides a certain success, i.e. the firm will dispose of a viable technology.

$\mathrm{R} \& \mathrm{D}$ is an ongoing process. This means that within a product life cycle, the $R \& D$ process for the next generation product may already start. In our model I may have an overlap of product cycles in the sense that one product is in the R\&D stage while the previous generation is on the market. Further, as $R \& D$ is uncertain, for a certain period it may be not clear which product is marketed. If the $\mathrm{R} \& \mathrm{D}$ process is successful, the new generation will be offered, otherwise it is the old product. In case that a firm has applied for patents on many technology ideas before having developed them to a mature

\footnotetext{
${ }^{11}$ See Blonder (2005).

${ }^{12}$ See Katznelson (2007).

${ }^{13}$ See $\S 201.07$, Manual of Patent Examining Procedures, USPTO, (August 2006), at http://www.uspto.gov/web/offices/pac/mpep/mpep.htm.
} 
technology, it can be lucky and be able to transform one of them into a product that is sold immediately. Then, the competitor is no more able to sell her product, unless she can also offer a new generation product.

\section{The Model}

In this section I present the basic model which is solved by backwards induction. This model will be extended in the subsequent section.

Assume that in a long $R \& D$ process the final product is marketed in the period following the $R \& D$ stage. This means that in the long $R \& D$ process the firm will have a product in the second period for sure but none during the $R \& D$ stage. In the first stage $R \& D$ is conducted and in the second period and possibly in the third period the product is marketed. In this example stage two is a pure marketing stage whereas stage three consists of both selling the product and conducting $\mathrm{R} \& \mathrm{D}$ for the next generation product. Thus, a cycle lasts for two periods until R\&D is conducted anew. I denote this strategy of firm $i$ by $L_{i}^{2}$ where the superscript denotes the number of periods until R\&D starts anew. I normalize the cost of this long R\&D process to zero.

A firm can choose the length of its product cycle, i.e. when it starts the $R \& D$ process anew. A short $R \& D$ process aims at introducing a new product in the same period in which the R\&D is conducted. Being successful the new product is marketed in the first stage, otherwise in the second. If a firm conducts $\mathrm{R} \& \mathrm{D}$ in each period and aims at offering a new generation product in each period, this cycle lasts only one period. The costs of the short R\&D strategy is proportional to the number of patent applications $N(p)$ where $p$ is the probability that the firm will have a successful technology in the R\&D period. Such a short R\&D strategy combined with a short cycle by firm $i$ is denoted $S_{i}^{1}$. 
The payoffs will depend on the strategy choices of the two firms. In order to take into account time, I discount with the factor $0<\delta<1$ per period. By assumption, all periods are of identical length. The simplest case arises when the firms choose symmetric strategies. If both firms choose $L_{i}^{2}$, this variable will also denote the payoff

$$
\begin{array}{r}
L_{1,2}^{2}=\pi^{D}+\delta \pi^{D}+\delta^{2} L_{1,2}^{2} \\
L_{1,2}^{2}=\frac{\pi^{D}}{1-\delta} .
\end{array}
$$

Basically, both firms offer identical products which are updated every other period. Consequently, they earn duopoly profit $\pi^{D}$ in every period.

Similarly, if both firms apply strategy $S_{i}^{1}$ they have identical expectations about each future period. However, as the R\&D processes are uncertain, the payoffs will depend on the R\&D outcomes. Either both firms, one, or none of them may be successful. If only one of the firms is successful we have the asymmetric case where the innovator will earn monopoly profits because by assumption only his product will meet demand like in Grossman and Helpman (1991). In the symmetric case, both firms choose the same strategy.

The success probability of a firm will depend on the number of its patent applications. Let $p_{i}$ denote the success probability of firm $i$ in the R\&D stage. Then $N\left(p_{i}\right)$ is the number of patent applications that are necessary in order to realize this probability. $N$ can be interpreted as the cost of patenting if the cost of one patent application is normalized to one. In order to guarantee that $p_{i} \in[0 ; 1]$, I assume $N$ being convex, $N(0)=0, \lim _{p \rightarrow 1} N(p)=\infty$. If the firms do not apply the short R\&D cycle or they are not successful in the short cycle, I assume that the firms obtain the relevant technology for sure in the subsequent period at zero cost. This normalization will simplify the 
further computations. The expected payoff for firm 1 will be

$$
\begin{gathered}
S_{1}^{1}=-N\left(p_{1}\right)+p_{1}\left(1-p_{2}\right) \pi^{M}+\left(1-p_{1}\right)\left(1-p_{2}\right) \pi^{D}+p_{1} p_{2} \pi^{D}+\delta S_{1}^{1} \\
\quad S_{1}^{1}=\frac{-N\left(p_{1}\right)+p_{1}\left(1-p_{2}\right) \pi^{M}+\left(1-p_{1}\right)\left(1-p_{2}\right) \pi^{D}+p_{1} p_{2} \pi^{D}}{1-\delta} .
\end{gathered}
$$

$p_{1}\left(1-p_{2}\right)$ is the probability of the case where firm 1 is successful, but firm 2 is not. In the opposite case, firm 1 earns zero profit. $\left(1-p_{1}\right)\left(1-p_{2}\right)$ is the probability that both firms take their augmented effort in vain. Still they earn duopoly profits because in the period after the previous R\&D stage both are certain to have a (pre-generation) product and earn duopoly profit. $p_{1} p_{2}$ is the probability that both firms successfully introduce a new product. For simplicity reasons I assume that the duopoly profit is the same as with the old product.

In the case that the firms have asymmetric strategies, I need further assumptions. Departing from an $L_{1,2}^{2}$ situation, assume that firm 1 chooses to switch to an $S_{1}$ strategy. If it finds it profitable in one period, it will be profitable in the next period, too, given that the competitor is still following an $L_{2}^{2}$ strategy. Thus, firm 1 would shorten his product cycle and the only sensible strategy would be $S_{1}^{1}$. Consequently, I need to consider an appropriate reaction of firm 2. If for firm 2 sticking to the $L_{2}^{2}$ strategy is still profitable, then she continues to have zero $R \& D$ costs but she yields a positive revenue only with probability $1-p_{1}$, when firm 1 is not successful. However, after having faced her competitor shortening his R\&D process firm 2 can switch to an $S_{2}$ strategy, too. For the same argument as above, if switching once to an $S_{2}$ strategy, when firm 1 follows an $S_{1}^{1}$ strategy, is profitable, it will be so in the next period, too, such that firm 2 would choose $S_{2}^{2}$. Summing up, either firm 2 reacts by adopting the same strategy as firm 1 or she does not change her behavior. Now, I can formulate the two payoffs. Let firm 1 choose $S_{1}^{1}$ 
while firm 2 sticks to the long research cycle with $L_{2}^{1}$. The payoff is

$$
S_{1}^{1}\left(L_{2}^{1}\right)=-N\left(p_{1}\right)+p_{1} \pi^{M}+\left(1-p_{1}\right) \pi^{D} .
$$

For firm 2 it is

$$
L_{2}^{2}\left(S_{1}^{1}\right)=\left(1-p_{1}\right) \pi^{D}
$$

\begin{tabular}{c|c|c} 
& \multicolumn{2}{|c}{$i=2$} \\
$i=1$ & $L_{2}^{1}, L_{2}^{2}$ & $S_{2}^{2}$ \\
\hline$L_{1}^{1}, L_{1}^{2}$ & $\pi^{D}$ & $\left(1-p_{2}\right) \pi^{D}$ \\
& $\pi^{D}$ & $-N\left(p_{2}\right)+p_{2} \pi^{M}+\left(1-p_{2}\right) \pi^{D}$ \\
\hline$S_{1}^{1}$ & $-N\left(p_{1}\right)+p_{1} \pi^{M}+\left(1-p_{1}\right) \pi^{D}$ & $-N\left(p_{1}\right)+p_{1}\left(1-p_{2}\right) \pi^{M}+\left(1-p_{1}\right)\left(1-p_{2}\right) \pi^{D}+p_{1} p_{2} \pi^{D}$ \\
& $\left(1-p_{1}\right) \pi^{D}$ & $-N\left(p_{2}\right)+p_{2}\left(1-p_{1}\right) \pi^{M}+\left(1-p_{2}\right)\left(1-p_{1}\right) \pi^{D}+p_{1} p_{2} \pi^{D}$
\end{tabular}

Table 1: Payoff matrix

In the following I will use the notation $\prod_{i}\left(x_{1}, x_{2}\right)$ for firm $i$ 's strategy with $x_{i} \in\{L ; S\}$ denoting $i$ 's strategy.

\subsection{Equilibria in the static game}

This subsection covers the strategy choice of the firms with respect to the length of the cycles. Depending on the magnitude of the payoffs, all combinations of actions can form an equilibrium.

It is not clear whether an $S$ strategy is profitable overall. But, comparing the payoffs immediately shows that being the only firm to follow an $S$ strategy is more profitable than if both firms do so. We can immediately see that

$$
\begin{array}{r}
-N\left(p_{1}\right)+p_{1}\left(1-p_{2}\right) \pi^{M}+\left(1-p_{1}\right)\left(1-p_{2}\right) \pi^{D}+p_{1} p_{2} \pi^{D}>\pi^{D} \\
-N\left(p_{1}\right)+p_{1} \pi^{M}+\left(1-p_{1}\right) \pi^{D}-p_{1} p_{2}\left(\pi^{M}-\pi^{D}\right)-\left(1-p_{2}\right) \pi^{D}>\pi^{D}
\end{array} \Leftrightarrow
$$


implies

$$
-N\left(\widetilde{p}_{1}\right)+\widetilde{p}_{1} \pi^{M}+\left(1-\widetilde{p}_{1}\right) \pi^{D}>\pi^{D}
$$

where $N\left(p_{1}\right)$ and $N\left(\widetilde{p}_{1}\right)$ denote the number of patent applications in the symmetric $S ; S$ and asymmetric $S ; L$ strategy choice, respectively. This means that if it is more profitable for both firms to choose the short cycle than both sticking to the long cycle, then each firm would prefer to be the only firm with the short cycle while the other stays with the long cycle.

However, whether an $S$ strategy is profitable overall, depends on the parameters, namely the success probabilities, the monopoly and duopoly payoffs, and the cost of R\&D. It is obvious that high costs of research or low monopoly payoffs will result in an $L ; L$ equilibrium. Conversely, if the prospective monopoly profit is high compared to the R\&D costs, then both firms may be willing to take a chance and both choose the short cycle $S$.

Lemma 1 A firm unilaterally choosing the short cycle $S$ applies for more patents than in the symmetric case where both firms choose $S: N\left(\widetilde{p}_{1}\right)>$ $N\left(p_{1}\right)$.

Proof Firm 1's payoff and the first order condition for $S ; L$ are

$$
\begin{array}{r}
-N\left(\widetilde{p}_{1}\right)+\widetilde{p}_{1} \pi^{M}+\left(1-\widetilde{p}_{1}\right) \pi^{D} \\
N^{\prime}\left(\widetilde{p}_{1}\right)=\pi^{M}-\pi^{D} .
\end{array}
$$

In the symmetric case $S ; S$ the payoff and the first order conditions are

$$
\begin{array}{r}
-N\left(p_{1}\right)+p_{1}\left(1-p_{2}\right) \pi^{M}+\left[\left(1-p_{1}\right)\left(1-p_{2}\right)+p_{1} p_{2}\right] \pi^{D} \\
N^{\prime}\left(p_{1}\right)=\pi^{M}-\pi^{D}-p_{2}\left(\pi^{M}-2 \pi^{D}\right) .
\end{array}
$$


$\pi^{M}-2 \pi^{D}>0$ because a monopolist can replicate two duopolists. Because of symmetry the arguments hold for firm 2 , too. Thus, $N\left(\widetilde{p}_{i}\right)>N\left(p_{i}\right)$ for $i=1,2$.

The more interesting cases arise when $\Pi_{1}(S ; L)>\Pi_{1}(L ; L)$ and $\Pi_{1}(L ; L)>$ $\Pi_{1}(S ; S)>0$ and the same holds for firm 2 . This means that both firms prefer to be the only firm employing the $S$ strategy but they are worse-off than under the $L ; L$ strategy if both choose $S$. This is a prisoners' dilemma. Given the $L ; L$ situation each firm has an incentive to unilaterally switch to $S$, but they will end up in the $S ; S$ case. $S ; S$ is a Nash-equilibrium with none of the firms having an incentive to unilaterally switch to the $L$ strategy. Formally, the prisoners' dilemma arises if

$$
\begin{aligned}
& \Pi_{1}(S, L)>\Pi_{1}(L, L) \\
& \Pi_{1}(L, L)>\Pi_{1}(S, S) \\
& \Pi_{1}(S, S)>\Pi_{1}(L, S)
\end{aligned}
$$

and the analogous conditions hold for $i=2$. I can show

Lemma 2 Given that the firms are symmetric and that $(p, p)$ is the symmetric Nash equilibrium for $\left(i \in\{1,2\}, N_{i} \in\left[0 ; \infty\left[, \Pi\left(N_{i}, N_{-i}\right)\right)\right.\right.$. Then a prisoners' dilemma will arise if

$$
N(p) \in\left[\left(p-p^{2}\right)\left(\pi^{M}-2 \pi^{D}\right) ;\left(p-p^{2}\right)\left(\pi^{M}-2 \pi^{D}\right)+p^{2} \pi^{D}\right]
$$

where $p_{1}=p_{2} \equiv p$ because of symmetry.

Proof We show that (10) through (12) is met. Because of symmetry it is sufficient to show that the conditions hold for one firm. 
(11) holds if

(14) $\pi^{D}>-N\left(p_{1}\right)+p_{1}\left(1-p_{2}\right) \pi^{M}+\left[\left(1-p_{1}\right)\left(1-p_{2}\right)+p_{1} p_{2}\right] \pi^{D}$

Using the symmetry $p_{1}=p_{2} \equiv p$ results in

$$
N\left(p_{1}\right)>\left(p-p^{2}\right)\left(\pi^{M}-2 \pi^{D}\right)
$$

which constitutes the lower bound in (13).

(10) holds for

$$
-N\left(\widetilde{p}_{1}\right)+\widetilde{p}_{1} \pi^{M}+\left(1-\widetilde{p}_{1}\right) \pi^{D}>\pi^{D}
$$

which is equivalent to

$$
N\left(\widetilde{p}_{1}\right)<\widetilde{p}_{1}\left(\pi^{M}-\pi^{D}\right)
$$

Applying the symmetry condition to (12)

(18) $-N\left(p_{1}\right)+p_{1}\left(1-p_{2}\right) \pi^{M}+(1-p) \pi^{D}+p_{1} p_{2} \pi^{D}>\left(1-p_{2}\right) \pi^{D}$

yields

$$
N\left(p_{1}\right)<\left(p-p^{2}\right)\left(\pi^{M}-\pi^{D}\right)+p^{2} \pi^{D} .
$$

Note that firm 1 faces $p_{2}$ if he unilaterally chooses $N\left(p_{1}\right)$ because firm 2 would still expect to be in the $S ; S$ situation. 
Now I show that (19) implies (17). Insert $\widetilde{p}_{1}=p$ in (17)

$$
L H S \equiv N(p)<p\left(\pi^{M}-\pi^{D}\right) \equiv R H S
$$

and compare with (19) rearranged as follows

$$
N(p)<p\left(\pi^{M}-\pi^{D}\right)-p^{2}\left(\pi^{M}-2 \pi^{D}\right) .
$$

(20) implies (21). For $\widetilde{p}_{1}>p$ the incremental change in (20) is

$$
\int_{p}^{\widetilde{p}_{1}} N(x) d x<\left(\widetilde{p}_{1}-p\right)\left(\pi^{M}-\pi^{D}\right)
$$

and the inequality holds because of (7) and convexity of $N$. Because (17) is weaker condition than (19) for $\widetilde{p}_{1}=p$ and (17) is further weakened for $\widetilde{p}_{1}>p$ conditions (15) and (19) define lemma (2).

\section{Existence of an Equilibrium}

Note that an equilibrium $(p, p)$ where $p>0$ not necessarily exists. Since we add no additional restriction on $N(\cdot)$ except strict convexity, it is possible that $N^{\prime}(0)>0$ exceeds the expected revenue from the first patent and thus, firms choose not to patent, $N=0$.

\subsection{Equilibria in the dynamic game}

Lemma 2 holds for a one-shot game with the payoff matrix given by Table 1. In a dynamic setting where the game is repeated perpetually, I need further assumptions on the firms' expectations. Unless otherwise stated, I will 
assume that firms expect that their competitor is sticking to his/her strategy unless they have a unilateral incentive to change. For a prisoners' dilemma the firms must be better-off under $L ; L$ than under $S ; S$, thus condition (11) must hold. Further, departing from $L ; L$ each firm has an incentive to choose $S$, and departing from $S ; L(L ; S)$ firm $2(1)$ has an incentive to match $S$. In the dynamic game the firms anticipate that unilaterally deviating from $L ; L$ will result in $S ; L$ for one period and $S ; S$ for all future periods because none of he firms will have an incentive to return to $L$ unilaterally. When deviating from $L ; L$ a firm will have to value a short term benefit of $\Pi_{1}(S, L)$ followed by an eternal flow of $\Pi_{1}(S, S)$ compared with a permanent profit $\Pi_{1}(L, L)$. Formally, the condition is

$$
\Pi(S, L)+\frac{\delta}{1-\delta} \Pi(S, S)>\frac{1}{1-\delta} \Pi(L, L)
$$

This is equivalent to

$$
\delta<\frac{\Pi(S, L)-\Pi(L, L)}{\Pi(S, L)-\Pi(S, S)} \equiv \bar{\delta}
$$

Lemma 3 There exists $\bar{\delta}$ such that a firm chooses $S$ for $\delta<\bar{\delta}$ and $L$ otherwise.

Proof From the assumption $\Pi(S, L)>\Pi(L, L)>\Pi(S, S)>\Pi(L, S)>0$ follows immediately $0<\bar{\delta}<1$.

The prisoners' dilemma can arise for $\delta<\bar{\delta}$ and the situation converges to the static setting for $\delta \rightarrow 0$. 


\subsection{Unilateral enforcement}

In this section, I analyze a firm's incentive to commit to a certain level of patent applications in order to deter other firms from deviating from the $L ; L$ situation. In the previous sections, I have considered Nash equilibria only. If a prisoners' dilemma arises, both firms prefer $L ; L$ to $S ; S$ but no firm has an incentive to unilaterally switch to $L$. Further, in an $L ; L$ situation, each of the firms would have an incentive to switch to $S$. Now, I discuss the strategy of a firm which can commit to a certain level of patent applications. For simplicity, I assume that firm 2 can commit to $\bar{p}_{2}$ in a credible way and firm 1 will observe and react upon $\bar{p}_{2}$. The same arguments hold for firm 1 in an analogous way. Given the situation $L ; L$ I analyze whether firm 2 is capable and has an incentive to choose another number of patent applications than in the Nash Equilibrium. In this scenario, first firm 2 sets $p_{2}$ and, subsequently, firm 1 chooses $L$ or $S$ and $p_{1}$.

In the situation with the prisoner's dilemma

$$
\Pi(S, L)>\Pi(L, L)>\Pi(S, S)>\Pi(L, S)
$$

holds true. In order to prevent firm 1's deviating from $L ; L$ the first inequality must be inverted such that

$$
\Pi(S, L) \leq \Pi(L, L)
$$

Clearly, in the static setting where the game ends after one period, there is no way to prevent the prisoners' dilemma. A commitment to $\bar{p}_{2}$ consists of firm $s$ 's commitment to set $\bar{p}_{2}$ in the $S ; S$ situation which would occur once one firm chooses $S$. If the game ends after the first period or $\delta=0$ the threat of setting $\bar{p}_{2}$ in a subsequent period is ineffective. 
I can show for the dynamic game

Lemma 4 There exists $\bar{\delta}\left(p_{2}\right)<1$ such that a firm with $\delta>\bar{\delta}\left(p_{2}\right)$ stays with the long research cycle $L$. Further, for $\delta \in[\underline{\delta} ; \bar{\delta}]$ firm 2 can enforce $L ; L$ by setting $p_{2} \in\left[p_{2}^{*} ; 1\right]$,

where $\bar{\delta}$ is defined in (24) and

$$
\underline{\delta}=\frac{-N\left(\widetilde{p}_{1}\right)+p_{1}\left(\pi^{M}-\pi^{D}\right)}{-N\left(\widetilde{p}_{1}\right)+p_{1}\left(\pi^{M}-\pi^{D}\right)+N\left(p_{1}\right)+\left(1-p_{1}\right) \pi^{D}}=\delta\left(p_{2}=1\right) .
$$

Proof Firm 2 does not choose $S$ if

$$
\begin{array}{r}
-N\left(\widetilde{p}_{1}\right)+\widetilde{p}_{1} \pi^{M}+\left(1-\widetilde{p}_{1}\right) \pi^{D} \\
+\frac{\delta}{1-\delta}\left(-N\left(p_{1}\right)+p_{1}\left(1-p_{2}\right) \pi^{M}+\left(1-p_{1}\right)\left(1-p_{2}\right) \pi^{D}+p_{1} p_{2} \pi^{D}\right) \\
\leq \frac{1}{1-\delta} \pi^{D} .
\end{array}
$$

or

$\delta \geq$

$\frac{-N\left(\widetilde{p}_{1}\right)+p_{1}\left(\pi^{M}-\pi^{D}\right)}{-N\left(\widetilde{p}_{1}\right)+\widetilde{p}_{1} \pi^{M}+\left(1-p_{1}\right) \pi^{D}-\left(-N\left(p_{1}\right)+p_{1}\left(1-p_{2}\right) \pi^{M}+\left(\left(1-p_{1}\right)\left(1-p_{2}\right)+p_{1} p_{2}\right) \pi^{D}\right)}$ $\equiv \delta\left(p_{2}\right)$.

If $p_{2}^{*}$ is the Nash-equilibrium $S ; S$, then

$$
\delta\left(p_{2}^{*}\right)=\frac{\Pi(S, L)-\Pi(L, L)}{\Pi(S, L)-\Pi(S, S)} \equiv \bar{\delta}
$$

and inserting $p_{2}=1$ yields

$$
\frac{-N\left(\widetilde{p}_{1}\right)+p_{1}\left(\pi^{M}-\pi^{D}\right)}{-N\left(\widetilde{p}_{1}\right)\left(\pi^{M}-\pi^{D}\right)+N\left(p_{1}\right)+\left(1-p_{1}\right) \pi^{D}} \equiv \underline{\delta}
$$


which proves the lemma.

Note that $p_{1}$ is a function of $\bar{p}_{2}$ because it is the best response of firm 1 with respect to $\bar{p}_{2}$. This lemma does not state that firm 2 can always enforce an $L ; L$ equilibrium. For $\delta<\delta(1)$ this will not be possible and the lower is $\delta$, the more patents firm 2 must apply for and, thus, the higher the cost that she must incur in order to ensure the $L ; L$ outcome.

$\bar{p}_{2}=1$ provides the least incentive for firm 1 to choose $S$ because he would never obtain the monopoly profit after the first period. However, this implies $N\left(\bar{p}_{2}\right)=\infty$. Thus, firm 2 is only willing to deter if it can do so with fewer patent applications and a lower probability $p_{2}<1$.

The deterministic interpretation requires that both firms have common knowledge about the parameters. If firm 2 has only information about the distribution of firm 1's parameters, she can form expectations about the effect of her number of patent applications on the probability of deterring firm 1. Then the marginal cost of an increase in firm 2's success probability must be compared to the marginal benefit from a reduced probability of firm 1 choosing $S$. This interpretation is valid under the assumption that the commitment to a constant number of patent applications $N\left(\bar{p}_{2}\right)$ over time is binding. Clearly, after realizing that $N\left(\bar{p}_{2}\right)$ is not high enough to deter 1 from $S$ firm 2 may want to revise its decision. This would imply an updating of firm 2's priors on 1.

The scenario for deterring bilateral intensive $R \& D$ relies on the assumption that firm 2 can commit to more intensive R\&D by herself as a retaliation strategy. The deterrence stage does not occur and no additional effort becomes necessary and no additional cost is incurred by firm 2. Thus, a credible commitment may be hard to realize. 
In the case, when the firms are already stuck in the prisoners' dilemma $S ; S$, they would prefer to return to the $L ; L$ situation because this is more beneficial to both of them. We demonstrate that there is no $0<p_{2} \leq 1$ such that firm 1 prefers $L$ to $S$ in the one shot static game.

Lemma 5 In the one shot game or $\delta=0$ firm 2 cannot commit to a level $\bar{p}_{2}$ such that firm 1 prefers to choose $L$ instead of $S$ in the Nash equilibrium $S ; S$.

Proof The asserted incentive is defined by

$$
\begin{array}{r}
\text { LHS } \equiv \\
\begin{array}{r}
\left(1-p_{2}\right) \pi^{D}>-N\left(p_{1}\right)+p_{1}\left(1-p_{2}\right) \pi^{M}+\left[\left(1-p_{1}\right)\left(1-p_{2}\right)+p_{1} p_{2}\right] \pi^{D} \\
\equiv R H S .
\end{array}
\end{array}
$$

For $p_{2}=0$ I have $\Pi(L ; L) \equiv \pi^{D}<-N\left(p_{1}\right)+p_{1} \pi^{M}+\left(1-p_{1}\right) \pi^{D}=\Pi(S ; L)$ which holds by assumption in the prisoners' dilemma because $i=1$ sets $p_{1}=p_{1}^{L}$. For $p_{2}=1 L H S=0<-N\left(p_{1}\right)+p_{1} \pi^{D}=R H S$. These limit values combined with

$$
\frac{\partial R H S}{\partial p_{2}}=-p_{1}\left(\pi^{M}-2 \pi^{D}\right)-\pi^{D}<-\pi^{D}=\frac{\partial L H S}{\partial p_{2}}
$$

where I apply the envelope theorem to $R H S\left(p_{1}\left(p_{2}\right) ; p_{2}\right)$, imply $L H S<$ RHS $\forall p_{2}$. Thus, for $p_{2} \in[0 ; 1]$ the assertion cannot hold.

In the dynamic setting, firm 2 can generate an incentive for firm 1 to switch and stick to strategy $L$ by the appropriate threat of setting $N\left(\bar{p}_{2}\right)$. The transition from $S ; S$ to $L ; L$ requires a commitment by firm 2 . If this commitment is credible it becomes effective immediately and Lemma (4) is 
relevant.

\section{Discussion}

This basic model shows that several situations may occur depending on the specifics of the market. If patenting costs are high or if firms can react only slowly such that remote periods are significantly discounted, firms tend to stick to the long R\&D cycle. This is in line with the observation in the automobile industry where before the introduction of computerized development, like computer aided design or crash test simulations, model cycles were longer than they are nowadays. By now, none of the major producers of automobiles did abstain from this technological progress.

Once the firms have adopted the higher patenting rate and shorter product cycles, they have no unilateral incentive to adopt the longer product cycle. This effect is not driven by demand because we neglect putative changes in customer preferences. Rather the high patenting frequency of a firm's competitor would drive her out of the market if she does not mimic the $S$ strategy.

Further, I have identified unilateral strategies that enforce a long cycle strategy. Such a strategy is only possible in a repeated setting where a commitment mechanism is available. This reflects the situation in typical product markets like, inter alia, automobile, household appliances, or computers. The static model is a reference case, but it can serve to understand emerging markets. In the software industry programming is realized in 24-hour-working days. ${ }^{14}$ Test versions and beta versions are launched in order to shorten the development time until marketing of new products. Here, firms face poten-

\footnotetext{
${ }^{14}$ See Kobitzsch et al. 2001.
} 
tial competition from innovators with similar products which are not yet in the market. Significant network effects, which are driven by consumer preferences, provide an incentive to introduce new products as early as possible because any lag behind a competitor may be fatal.

In the reference case all firms are identical. In the extension where one firm can commit to a particular number of patent applications I give up the symmetry assumption. This can refer to a case where a firm is acquired by another company with a more rigorous patenting strategy. We observe that some firms are very active in patenting where others are not. Texas Instruments, Lucent or IBM for example apply for many more patents than firms in the same product market and they are more brisk in defending their patent rights in litigation (Thomas (2001)).

The prisoners' dilemma is one potential Nash equilibrium. It can occur for some parameter ranges and I provided arguments that in some example industries this equilibrium may not have occurred if none of the active firms had launched the short R\&D cycle. In the following we extend the reference model.

\section{Extensions}

\subsection{Network Effects}

Network effects are driven by market demand because the consumers' utility increases increases with the number of consumers of the same product. Katz and Shapiro (1985) show in a one-period strategic game that the consumers' expectations about which product will be dominant can determine which product actually will be successful. In the context of infinitely many discrete periods Ofek and Sarvary (2003) introduce an exogenous reputation effect 
which is not based on the technology or the R\&D productivity and that gives the incumbent firm an advantage over its competitors. The reputation advantage has similar effect as the network effect as I model it here because an incumbent benefits from being active on the market before the competitors. In their model, an intermediate or high reputation effect raises the success probability in the subsequent period. This reduces the R\&D investment productivity and thus the incumbent firm spends less effort the the greater the reputation advantage. Similarly, Dasgupta (1986) shows that success in $R \& D$ leads to a higher success rate in subsequent periods. The present model comprises this "success breeds success" effect in the sense that both firms may be successful in the R\&D activities, but having had success in the previous period gives that firm an additional advantage.

I modify the basic model in order to cover this effect. Assume that the firms have identical products but one has launched her product before the other. Then the first product will face more demand because consumers expect that other consumers choose this product, too. For simplicity, I assume that the earlier product continues to earn monopoly profit when firms offer identical products. This is the case if firm $i$ was successful in time $t-1$ and the other was not, and in time $t$ both firms have no success in the R\&D activities and they are forced to cell their old products. This means that when both firms are not successful in their R\&D they will continue to earn the same profit as they did in the previous period. If at least one firm is successful the payoffs remain the same as in the reference model: If exactly one of the firms is successful it will earn monopoly profit and if both are successful both earn duopoly profit.

These changes require a modification of the payoff structure because the payoff in one period depends on the success or failure in the previous period. 
Thus, I can reformulate the condition for firm 1 to switch to $S$ :

$$
\widetilde{\Pi}(S ; L)+\frac{\delta}{1-\delta} \widetilde{\Pi}(S ; S)>\frac{1}{1-\delta} \Pi(L ; L)
$$

and I can show

Lemma 6 (i) Compared to the reference model, the presence of network effects raises the number of patent applications in the first short R\&D cycle. (ii) The number of patent applications tends to fall in subsequent periods when all firms opt for the short RED cycle. (iii) When both firms opt for the short RED cycle the incentive to patent is higher than absent network effects if firms earn duopoly profits in the preceding period.

Proof We change notation in for this subsection such that the superscript $t$ denotes the time period where 0 is the stage in which firm 1 may switch to $S$. The payoffs in the first four periods are

$$
\begin{aligned}
& \widetilde{\Pi}^{0}(S ; L)=-N\left(p_{1}^{0}\right)+p_{1}^{0} \pi^{M}+\left(1-p_{1}^{0}\right) \pi^{D} \\
& \frac{\widetilde{\Pi}^{1}(S ; S)}{\delta}=-N\left(p_{1}^{1}\right)+p_{1}^{1}\left(1-p_{2}^{1}\right) \pi^{M}+p_{1}^{1} p_{2}^{1} \pi^{D} \\
& +\delta\left(1-p_{1}^{1}\right)\left(1-p_{2}^{1}\right)\left[p_{1}^{0} \pi^{M}+\left(1-p_{1}\right)^{0} \pi^{D}\right] \\
& \frac{\widetilde{\Pi}^{2}(S ; S)}{\delta^{2}}=-N\left(p_{1}^{2}\right)+p_{1}^{2}\left(1-p_{2}^{2}\right) \pi^{M}+p_{1}^{2} p_{2}^{2} \pi^{D} \\
& +\delta\left(1-p_{1}^{2}\right)\left(1-p_{2}^{2}\right)\left[p_{1}^{1}\left(1-p_{2}^{1}\right) \pi^{M}+\left(1-p_{1}^{1}\right)\left(1-p_{2}^{1}\right) \pi^{D}+p_{1}^{1} p_{1}^{1} \pi^{D}\right] \\
& \frac{\widetilde{\Pi}^{3}(S ; S)}{\delta^{3}}=-N\left(p_{1}^{3}\right)+p_{1}^{3}\left(1-p_{2}^{3}\right) \pi^{M}+p_{1}^{3} p_{2}^{3} \pi^{D}
\end{aligned}
$$$$
+\delta\left(1-p_{1}^{3}\right)\left(1-p_{2}^{3}\right)\left[p_{1}^{2}\left(1-p_{2}^{2}\right) \pi^{M}+\left(1-p_{1}^{2}\right)\left(1-p_{2}^{2}\right) \pi^{D}+p_{1}^{2} p_{1}^{2} \pi^{D}\right]
$$

The first order condition with respect to $p_{1}^{0}$ in the period $t=0$ is

$$
N^{\prime}\left(p_{1}^{0}\right)=\left(\pi^{M}-\pi^{D}\right)+\delta\left(1-p_{1}^{1}\right)\left(1-p_{2}^{1}\right)\left(\pi^{M}-\pi^{D}\right) .
$$


We immediately see that $p_{1}^{0}$ exceeds $p_{1}$ in the first order condition absent network effects $N^{\prime}\left(p_{1}\right)=\pi^{M}-\pi^{D}$. This proves part (i).

In the periods $t \geq 1$ the firms' incentive to apply for patents depends on the outcome of the previous period. Since both firms apply the short R\&D cycle, patenting becomes less productive for firm 1 in expectations because if firm 2 is successful, firm 1 earns duopoly profit at best. The presence of a patenting competitor reduces the incentive to apply for patents after the first period (ii).

If a firm earns duopoly profit in a period $t-1$ the marginal revenue from patenting is equal to the incentive absent network effects plus the expected payoff in $t+1$. Thus the incentive is higher than absent the network effects (iii). If a firm earns monopoly profit in a period $t-1$ the marginal revenue in $t$ from patenting is lower than the incentive absent network effects because if both firms are not successful, this firm still earns monopoly profit. This diminished incentive may be compensated by the incentive to obtain an expected payoff in $t+1$ but which effect dominates is not clear.

For each firm there are three different states: monopoly, duopoly, or zero profit. Therefore, the exact incentive for a firm to patent depends on the outcome of the previous period. This will determine the incentive to patent in the current period because it is sensible to assume that firms observe each other's number of patent applications prior to choose their own action. Further, it remains unclear whether in the long run, more patents are filed under the presence of network effects than without but there is an intuitive argument in favor of a higher level of patenting: Network effects render the monopoly position more attractive because this position may be preserved throughout the following period. While the monopolist has a lower incen- 
tive to patent because of the Arrow-effect, ${ }^{15}$ the competitor has an increased incentive to avoid the zero profit situation in the subsequent period. Thus, monopoly profit tends to occur more often when network effects are present because even with two successful firms only the one with success in the previous period will earn monopoly profits. Since $\pi^{M}>2 \pi^{D}$ the market value is raised and this overall raises the incentive to compete for the market by investing more in $\mathrm{R} \& \mathrm{D}$ and applying for more patents.

Besides the effect on the patent propensity, we observe similar effects to the innovative advantage and the reputation advantage in Ofek and Sarvary (2003). In their model the reputation effect decreases the firms' incentive to invest in $\mathrm{R} \& \mathrm{D}$. The substitution effect reduces the incumbent's incentive to innovate. But the higher R\&D productivity may still result in a higher R\&D effort, unless the innovative advantage becomes so important such that the laggard cannot catch up and this would mitigate the leaders R\&D incentive. Similarly, the network effect in the present model leads to the effect that the technology leader has less incentive to invest.

\subsection{Blocking Patents}

Blocking patents are one aspect of patent thickets. Letting aside uncertainty and the holdup problem, I focus on the patent thicket as an overlapping set of patent rights. In order to commercialize a product a company must disentangle a web of intellectual property rights; this situation can cause the detrimental effect of discouraging innovation. ${ }^{16}$ The existence of overlapping intellectual property rights results in an inevitable infringement of external patents when fully taking advantage of the own patent's scope. Avoiding litigations or a holdup requires that the own patent cannot be exploited to

\footnotetext{
${ }^{15}$ See Tirole(1988).

${ }^{16}$ See Shapiro (2001).
} 
the entire extent. Therefore, some patents my lie idle after a firm has invested R\&D effort for this patent.

We introduce this effect in our model by awarding each patent a supplemental blocking effect on the competitor's patents. Again, I will concentrate on the incentives for one firm, understanding that the effects for the other is symmetric. Patent applications $N\left(p_{i}\right)$ by firm $i$ will block patents by firm $j$ with probability $\beta p_{i}$ where $\beta \in[0 ; 1]$. This means that $j$ 's success probability is reduced by the factor $\beta p_{i}$ and only the share $\left(1-\beta p_{i}\right) p_{j}$ is the effective success probability of firm 2 .

The cases $L ; L$ and $S ; L$ remain unaltered compared to the reference model because firm 2 has no patent applications which, by assumption, may interfere with firm 1's patent applications.

\begin{tabular}{c|cc|cc|cc} 
& \multicolumn{2}{|c|}{ no blocking (A) } & \multicolumn{2}{c}{$i=1$ blocking (B) } & \multicolumn{2}{c}{$i=1,2$ blocking (C) } \\
& probability & payoff & probability & payoff & probability & payoff \\
\hline (a) & $p_{1}\left(1-p_{2}\right)$ & $\pi^{M}$ & & & $\begin{array}{c}\beta p_{2} \\
\left(1-\beta p_{2}\right)\end{array}$ & $\begin{array}{c}\pi^{D} \\
\pi^{M}\end{array}$ \\
\hline (b) & $\left(1-p_{1}\right)\left(1-p_{2}\right)$ & $\pi^{D}$ & & & & \\
\hline$\left(\mathrm{c}_{1}\right)$ & $p_{1} p_{2}$ & $\pi^{D}$ & $\beta p_{1}$ & $\pi^{M}$ & $\beta p_{2}$ & $\pi^{D}$ \\
$\left(\mathrm{c}_{2}\right)$ & & & $\left(1-\beta p_{1}\right)$ & $\pi^{D}$ & $\begin{array}{c}(1-\beta) p_{2} \\
\left(1-\beta p_{2}\right.\end{array}$ & $\pi^{M}$ \\
& & & & & & \\
\hline (d) & $\left(1-p_{1}\right) p_{2}$ & 0 & $\beta p_{1}$ & $\pi^{D}$ & & \\
\hline
\end{tabular}

Table 2: Payoff for $i=1$ with Blocking Patents

Table 2 shows for the $S ; S$ situation the payoffs and the respective probabilities of firm 1 absent blocking patents $L ; L$, only 1 blocking $S ; L$, and 1 and 2 blocking $S$; $S$, in columns $A, B$, and $C$, respectively. (A) is the situation where there are not conflicting intellectual property rights. Column (B) indicates the effect of firm 1's patent applications on the expected 
payoffs. These patents can neutralize firm 2's patents and, thus, transforming a duopoly profit into a monopoly profit or a zero profit into a duopoly. Column (C) adds the effect of firm 2's patent applications which potentially block firm 1's patents.

Rewriting the payoff absent blocking patents

$\Pi(S, S)=$

$-N\left(p_{1}\right)+\underbrace{p_{1}}\left(1-p_{2}\right) \pi^{M}+\left(1-p_{1}\right)\left(1-p_{2}\right) \pi^{D}+\underbrace{p_{1} p_{2}} \pi^{D}+\left(1-p_{1}\right) \underbrace{p_{2}} 0$

allows to mark the successful $R \& D$ activities that may be subject to conflicting applications by the competitor. We add the last term equal to zero for illustrative purpose only because introducing the blocking effect may render it positive with some probability. This payoff function is amended by the situations where one or both firms are blocking their competitor's patents. Then the payoff is

$$
\begin{array}{r}
\widetilde{\Pi}(S ; S)=-N\left(p_{1}\right)+p_{1}\left(1-p_{2}\right)\left[\beta p_{2} \pi^{D}+(1-\beta) \pi^{M}\right]+\left(1-p_{1}\right)\left(1-p_{2}\right) \pi^{D} \\
+p_{1} p_{2}\left[\beta p_{1}\left(\beta p_{2} \pi_{D}+\left(1-\beta p_{2}\right) \pi^{M}\right)+\left(1-\beta p_{1}\right)\left(1-\beta p_{2}\right) \pi^{D}\right] \\
+\left(1-p_{1}\right) p_{2} \beta p_{1} \pi^{D}
\end{array}
$$

which simplifies to

$$
\begin{array}{r}
\widetilde{\Pi}(S ; S)=-N\left(p_{1}\right)+\Pi(S ; S) \\
-\beta p_{1} p_{2}\left[\left(1-p_{1}-p_{2}+p_{1} p_{2} \beta\right)\left(\pi^{M}-2 \pi^{D}\right)\right]
\end{array}
$$

where $\Pi(S ; S)=p_{1}\left(1-p_{2}\right) \pi^{M}+\left(1-p_{1}\right)\left(1-p_{2}\right) \pi^{D}+p_{1} p_{2} \pi^{D}$ is the profit of the reference model wheref both firms choose the short $R \& D$ cycle.

Proposition 1 The effect of blocking patents (i) on the number of patent 
applications is negative, (ii) on overall profit is negative if $2 p-\beta p^{2}<1$ and positive otherwise, (iii) on consumer surplus and the probability of a prisoners' dilemma is inverse to (ii). Thereby $p=p_{1}=p_{2}$ is the symmetric equilibrium of the game $\left(i \in\{1,2\}, N_{i} \in\left[0 ; \infty\left[, \widetilde{\Pi}\left(N_{i}, N_{-i}\right)\right)\right.\right.$.

Proof For (i) assume that $p_{2}>p_{2}^{O}$ where $p^{O} \equiv p_{2}^{O}=p_{1}^{O}$ is the equilibrium of the benchmark game in Lemma 2 absent blocking effects. The first order condition of (33) for firm 1 is

$N^{\prime}\left(p_{1}\right)=\pi^{M}-\pi^{D}-p_{2}\left(\pi^{M}-2 \pi^{D}\right)-\beta p_{2}\left(\pi^{M}-2 \pi^{D}\right)\left[1-2 p_{1}-p_{2}+\beta p_{2} p_{2}\right]$

$$
\equiv M R \text {. }
$$

The right hand side denotes 1's marginal revenue. Then,

$$
\begin{array}{r}
\frac{\partial M R}{\partial p_{2}}=-\left(\pi^{M}-\pi^{D}\right)- \\
\quad(35) \quad=\left(\pi^{M}-2 \pi^{D}\right)\left(1-2 p_{2}\right)+p_{1} 2 \beta\left(\pi^{D}\right)\left[-1-\beta\left(-1+2 p_{2}+2 p_{1}-4 p_{1} p_{2}\right)\right]<0
\end{array}
$$

for $p \equiv p_{1}=p_{2}$ (symmetry) and any $0 \leq \beta \leq 1$. For $p_{2}>p^{O}$ we have $N^{\prime}\left(p_{1}\right)=M R^{\prime}<M R$ and, thus, $p_{1}<p^{O}$. Because of symmetry $p_{1}=p_{2}$ which contradicts the assertion $p_{2}>p^{O}$.

For (ii), recall that firm $i$ 's number of patent applications is determined by the first order condition of (33) with respect to $p_{i}$ which is $\partial \widetilde{\Pi}(S ; S) / \partial p_{i}=0$. For $\beta=0$ (33) is equivalent to (6). Applying the envelope theorem on

$$
\frac{\partial \widetilde{\Pi}\left(p_{1}(\beta), \beta\right)}{\partial \beta}=\frac{\partial \widetilde{\Pi}}{\partial p_{1}} \frac{\partial p_{1}}{\partial \beta}+\frac{\partial \widetilde{\Pi}}{\partial \beta}
$$


simplifies to

$$
\frac{d \widetilde{\Pi}}{d \beta}=-p_{1} p_{2}\left[1-p_{1}-p_{2}+\beta p_{1} p_{2}\right]\left(\pi^{M}-2 \pi^{D}\right)<0 .
$$

which holds in a symmetric equilibria $p_{1}=p_{2} \equiv p$ for $2 p-\beta p^{2}<1$.

For (iii) note that there are only two states for the provision, namely duopoly and monopoly. A lower expected payoff implies that duopoly becomes more probable. Thus welfare increases and lowers the probability of a prisoners' dilemma because $\widetilde{\Pi}(S ; S)$ in $(24)$ decreases.

The blocking effect of patents decreases the productivity of $R \& D$ because the blocking effect increases the probability that an application becomes obsolete. This effect reduces the number of patent applications of the competitor. However, this latter effect is dominated by the productivity effect. Clark and Konrad (2006) find this effect in a model of a contest where a marketable product builds on multiple, complementary patents. They predict that R\&D effort is reduced in the light of upcoming hold-up situations.

The effect of the blocking property on the firms' overall expected profit is ambiguous. For small numbers of patent applications, $p<1 / 2$, amplifying the blocking effect will always reduce the firms' profit, i.e. a duopoly becomes more probable because this will preempt the competitor to achieve a marketable innovation. An aggravation of the blocking effect when firms apply for many patents will raise the probability of monopoly profits because one competitor is more likely to be blocked.

Overall profits and welfare perform in an idiosyncratic way because we assume that duopoly with new and old products generate the same profits and welfare. This is a strong assumption because an indefinite duopoly with outdated products would generate the same welfare as an incessant product 
improvement. Raising prices and costs may attenuate this objection. Actually, in some markets we observe significant price escalations, for example in the automobile industry, whereas other industries like semiconductors we observe quality improvements but approximately constant prices for PCs.

The implications for the probability of a prisoners' dilemma is technically based on the magnitude of the expected firms' profit in the $S$; $S$ situation. Changes in $\widetilde{\Pi}(S ; S)$ make it more or less attractive to leave the $L ; L$ situation. Thus, a policy that ensures that a pure duopoly arises under the $S ; S$ schedule makes it less attractive to deviate from an $L ; L$ situation.

Mutually blocking patents create an incentive to licensing in order to make the blocked technologies accessible. Licensing helps solving patent thickets when all parties agree not to litigate against potential infringement. There are two types of licensing, ex ante licensing and ex post licensing, which differ by the timing of the licensing agreement relative to the timing of the $R \& D$ investment. For the semi-conductor industry Siebert and von Graevenitz (2006) find that most agreements involve ex ante licensing. But there is also evidence for ex post licensing, i.e. agreements after the parties have built up patent stocks which have mutually blocking effects (Lerner and Tirole (2004), Ziedonis (2004)).

Introducing ex ante licensing in the present model setting means that a firm could not gain an advantage over her competitor and thus, has no incentive to file a costly patent application. Thus, an ex ante licensing agreement would stabilize long research cycles with low R\&D incentives. This gives rise to antitrust issues because such an agreement may be considered anticompetitive. Lerner and Tirole (2004) focus on this discussion and provides conditions under which a patent pool is efficiency enhancing. This is even more the case if patents are complementary assets. We see that transforming R\&D effort into a public good immediately paralyzes R\&D. An evaluation 
of ex ante licensing requires a richer modeling of demand in order to assess the welfare effect of reduced innovative activities.

Under ex post licensing negotiations take place after firms have set up their patent portfolios. In the present model, this can be interpreted as incorporating technologies which would have lied idle otherwise. This is welfare enhancing in the most cases. Still antitrust issues may arise when cross licensing has a potential to enforce higher marginal cost and higher than competitive prices on the product market. The U.S. Antitrust Guidelines of the Licensing of Intellectual Property aim at preventing such behavior. ${ }^{17}$

Besides antitrust issues, ex post licensing can also distort R\&D incentives. Anticipating hold-up situation may be an additional motive for patenting, in particular in industries which tend to build up patent thickets (Ziedonis (2004)). An R\&D strategy that aims at creating pure complementarities in order to secure a share in the competitor's achievement or in order to obtain a better position in subsequent negotiations may induce socially wasteful effort. Therefore, going for blocking patents instead of differentiating technologies constitutes an insurance against being blocked oneself, even if the blocking patent does not contribute to one own's technology. Even absent blocking effects of patents Gerlach et al. (2004) analyze the R\&D incentives to go for mainstream or niche products where $R \& D$ success is uncertain. They find that firms tend to aim more at mainstream products than socially desirable. Similarly, Cardon and Sasaki (1998) find that R\&D tend to cumulate on single technologies more than socially desirable instead of aiming at differentiated markets.

\footnotetext{
${ }^{17} \mathrm{http}: / /$ www.usdoj.gov/atr/public/guidelines/0558.htm
} 


\section{Conclusion}

The analysis has shown that shorter product cycles can induce more patenting activities. This provides a counter argument to the intuitive reaction of patenting less when the time is shortened during which the $R \& D$ investment must be recouped or a secret idea may be discovered and replicated. The underlying mechanism for the more intensive patenting activity is that one firm may start to patent for exogenous reasons and the optimal reaction of other firms is then to match this behavior. Otherwise, the extensive patenting of one firm would drive the other firms out of the market or cut their profits significantly. In order to prevent this, the other firms will file patent applications on ideas which may not be mature yet. If this situation occurs the firms may end up in a prisoners' dilemma where they would jointly prefer the situation where all firms innovate at moderate pace but each individual firm has an incentive to deviate to a short cycle with intensive patenting.

Further, network effects may reinforce a firm's incentive to accelerate her R\&D process and to induce other firms to adopt this strategy. Network effects make it more attractive to gain market shares at an early stage because an advance compared to the competitors will be persistent. Therefore, the model predicts an intensive race by means of patent applications followed by a period of weakened innovative activities.

Similarly, blocking patents provide an advantage over competitors by limiting their access to technologies. But, in contrast to network effects, this is socially harmful because some $\mathrm{R} \& \mathrm{D}$ effort is wasted. Therefore, firms will patent less because their R\&D tends to be less efficient. Also, a monopoly position becomes less probable if the blocking effect is strong.

Welfare implications are restricted to the pace of technological development because the modeling of demand behavior limits further interpretation 
of consumer welfare. There is an immediate welfare loss from the blocking effect which inhibits patented technologies from being incorporated in marketed products. Moreover, over time patents and patent applications accumulate and the delayed publication 18 months after first filing creates uncertainty. This may create a patent thicket. Once this occurs, this may deter active firms from further research or potential entrants from engaging in this technology. The uncertainty is even increased when firms apply through the WIPO where an applicant can delay its decision to seek for protection for up to 18 further months compared to the procedure through national patent offices.

In the present model we do not tackle the question about the optimal amount of innovation. Usually, it is assumed that more innovation is better than less. Then a policy which promotes more innovation is beneficial. On the level of the patent examination process a blocking patent cannot be identified because the blocking property becomes relevant when the patent technology is used in a product. Therefore, licensing as an instrument to solve up blocking effects should be facilitated. This holds in particular for technology areas where patent thickets emerge. 


\section{References}

Agarwal R., M. Gort (2001), First-Mover Advantage and the Speed of Competitive Entry, 1887-1986, in: Journal of Law and Economics 44(1), 161-177.

Aghion, P., P. Howitt (1992), A Model of Growth Through Creative Destruction, in: Econometrica 60(2), 323-351.

Blonder, G. 2005), Cutting Through the Patent Thicket, in: BusinessWeek, December 20.

Cohen, W.M., R.R. Nelson and J.P. Walsh (2000), Protecting their Intellectual Assets: Appropriability Conditions and Why U.S. Manufacturing Firms Patent (or not), NBER Working Paper No. 7552.

Dasgupta, P. (1986), The Theory of Technological Competition, in: J.E. Stiglitz, G.F. Mathewson, eds., New Developments in the Analysis of Market Structure, MIT Press, Cambridge MA, 519-549.

Clark D.J. and K.A. Konrad (2006), Fragmented property rights and incentives for R\&D,in: Management Science, 54(5), 969-981.

Gallini, N. (2002), The Economics of Patents: Lessons from Recent U.S. Patent Reform, in: Journal of Economic Perspectives 16(2), 131-154.

Gjerde, K.A.P., S.A. Slotnick, and M.J. Sobel (2002), New Product Innovation with Multiple Features and Technology Constraints, in: Management Science 48(19), 1268-1284.

Grossman, G.M. and E. Helpman (1991), Quality Ladders and Product Cycles, in: QJE 106(2), 557-586. 
Heller, M.A. and R.S. Eisenberg (1998), Can Patents Deter Innovation? The Anticommons in Biomedical Research, in: Science 280, 698-701.

Katz, M.L. and C. Shapiro (1985), Network Externalities, Competition, and Compatibility, in: AER 75(3), 424-440.

Katznelson, R.D. (2007), Patent Continuations, Product Lifecycle Contraction and the Patent Scope Erosion - A New Insight into Patenting Trends. Southern California Law Associations Intellectual Property Spring Seminar, June 8-10, 2007, http://ssrn.com/abstract=1001508

Kobitzsch, W., D. Rombach and R.L. Feldmann (2001), Outsourcing in India, in: IEEE Software 18(2), 78-86.

Kortum, S. and J. Lerner (1998), Stronger Patent Protection and Innovations: What is Behind the Recent Surge in Patenting?, in: CarnegieRochester Conference Series on Public Policy, Vol. 48, 247-304.

Langer, A., N.H. Miller (2008), Automobile Prices, Gasoline Prices, and Consumer Demand for Fuel Economy, mimeo, UC Berkeley.

Lerner, J. and J. Tirole (2004), Efficient Patent Pools, in: AER 94(4), 691711.

Merges, R.P. and R.R. Nelson (1990), On the Complex Economics of Patent Scope, in: Columbia Law Review 90, 4, 839-916.

Ofek, E. and M. Sarvary (2003), R\&D, Marketing, and the Success of NextGeneration Products, in: Marketing Science 22(3), 355-370.

Tirole, J. (1988), The Theory of Industrial Organization, MIT Press.

Mussa, M. and S. Rosen (1978), Monopoly and Product Quality, in: Journal of Economic Theory 18, 301-317. 
Pisano G, D.J. Teece (2007), How to Capture Value from Innovation: Shaping Intellectual Property And Industry Architecture, in: California Management Review 50(1), 278-296.

Reinganum, J. (1989), The Timing of Innovation: Research, Development, and Diffusion, in: R. Schmalensee and R.D. Wittig, eds., Handbook of Industrial Organization, Vol. 1, 849-908.

Sabety, T. (2005), Nanotechnology and the Patent Thicket: Which IP Policies Promote Growth?, in: Albany Law Journal of Science \& Technology $15,477-515$.

Sanyal, P. and A.B. Jaffee (2007), Peanut Butter Patents Versus the New Economy: Does the Increased Rate of Patenting Signal More Invention or Just More Lawyers?, Annales d'Èconomie et de Statistique, forthcoming.

Segerstrom, P.S., T.C.A. Anant and E. Dinopoulos (1990), A Schumpeterian Model of the Product Life Cycle, in: AER 80(5), 1077-1091.

Scotchmer, S. (2004), Innovation and Incentives, MIT Press.

Shaked, A. and J. Sutton (1982), Relaxing Price Competition Through Product Differentiation, in: Review of Economic Studies 49, 3-13.

Shaked, A. and J. Sutton (1983), Natural Oligopolies, in: Econometrica 51(5), 1469-1483.

Shapiro, C. (2001), Navigating the Patent Thicket: Cross Licenses, Patent Pools, and Standard Setting, in: A.B. Jaffe, J. Lerner and S. Stern eds., Innovation Policy and the Economy, vol.1, MIT Press, 119-150. 
Siebert R. and G. von Graevenitz (2006), Jostling for Advantage: Licensing and Entry into Patent Portfolio Races, CEPR Discussion Paper No. 5753 .

Teece, D.J., G. Pisano, A. Shuen (1997), Dynamic Capabilities and Strategic Management, in: Strategic Management Journal 18(7), 509-533.

Thomas, P. (2001), A relationship between technology indicators and stock market performance, in: Scientometrics 51(1), 319-333.

Vernon, R. (1966), International Investment and International Trade in the Product Cycle, in: QJE 80(2), 190-207.

Ziedonis, R.H. (2004), Don’t Fence Me In: Fragmented Markets for Technology and the Patent Acquisition Strategies of Firms, in: Management Science 50(6), 804-820. 